\title{
PENINGKATAN PENGETAHUAN KANKER PAYUDARA PADA MASYARAKAT DESA RANCAMANYAR KABUPATEN BANDUNG
}

\author{
Hesti Lina Wiraswati' ${ }^{12}$, Savira Ekawardhani' ${ }^{12}$,Sarasati Windria ${ }^{34}$, Lia Faridah ${ }^{24}$, Syafrizal Saragih', \\ Muhammad Saifuddin B. S. Arif ${ }^{1}$, Meri Alex Sandra ${ }^{1}$, Astri Gloria Larwuy ${ }^{1}$, Dini Oktaviani ${ }^{1}$, Yasfira \\ Aradella $^{1}$, Salma Nur Raidah ${ }^{1}$ \\ ${ }^{1}$ Pusat Studi Onkologi dan Sel Punca, Fakultas Kedokteran, Universitas Padjadjaran \\ ${ }^{2}$ Divisi Parasitologi, Departemen Ilmu Kedokteran Dasar, Fakultas Kedokteran, Universitas Padjadjaran, \\ ${ }^{3}$ Divisi Mikrobiologi, Departemen Ilmu Kedokteran Dasar, Fakultas Kedokteran, Universitas Padjadjaran, \\ ${ }^{4}$ Pusat Studi Infeksi, Fakultas Kedokteran, Universitas Padjadjaran \\ E-mail: hesti.lina@unpad.ac.id
}

\begin{abstract}
ABSTRAK. Meningkatnya kasus kanker dan kematian akibat kanker di Indonesia dari tahun ke tahun perlu mendapatkan perhatian serius. Faktor penting yang berkontribusi pada peningkatan kejadian ini adalah kurangnya sosialisasi tentang kanker, penyebab kanker dan aktivitas-aktivitas penurun resiko kanker, disamping kurang efektifnya pengobatan dan upaya peningkatan kualitas hidup penderita. Oleh karena itu penelitian ini bertujuan untuk meningkatkan wawasan masyarakat tentang penyakit kanker, termasuk penyebab kanker dan faktor-faktor penurun resiko kanker sehingga diharapkan akan meningkatkan kesadaran dan kewaspadaan masyarakat agar terhindar dari penyakit ini. Kegiatan yang dilakukan dalam penelitian ini adalah berupa penyuluhan yang berbasis metode pendidikan masyarakat dengan berbagai macam aktivitas diantaranya ceramah, diskusi, nonton video, dan tanya jawab berhadiah. Pre-test dan post-test digunakan sebagai alat ukur untuk melihat ketercapaian tujuan. Hasilnya pertama, terjadi peningkatan pemahaman peserta rata-rata $23 \%$, dengan rentang pemahaman 34\%-89\%. Kedua, selama diskusi peserta menyatakan sikapnya untuk bergaya hidup sehat agar memperkecil resiko terkena kanker payudara. Hasil-hasil tersebut menunjukkan bahwa penyuluhan yang dilakukan mampu meningkatkan pemahaman masyarakat tentang kanker dan memunculkan kesadaran masyarakat untuk berpola hidup sehat sebagai bentuk upaya pencegahan kanker payudara.
\end{abstract}

Kata kunci: kanker payudara; penyebab kanker; aktivitas penurun resiko kanker

ABSTRACT. Increased cancer cases and cancer deaths in Indonesia need serious attention. Important factor that contributes to this situation is less information about cancer including correct understanding about cancer, the cause of cancer, and how to reduce cancer risk, in addition to the lack of effective treatment and efforts to improve the life quality of patients. Therefore this study aims to improve public insight into cancer, reduction factors of cancer risk, and early detection of breast cancer so that it is expected to increase public awareness to avoid this disease. The methods in this study were based on community education with various activities including lectures, discussions, watching videos, and doorprices session. Pre-test and post-test questionnaires were used as a tool to measure the goals achievements. The result showed increasing understanding of participants by an average of $23 \%$, with an understanding range from $34 \%$ to $89 \%$. Second, during the discussion participants stated their affective to improve the lifestyle so as to minimize the risk of breast cancer. These results indicate that that study is quite successful to improve people's understanding of cancer and raise public awareness to have healthy lifestyle as a form of breast cancer prevention efforts.

Key words: breast cancer; cause of cancer; cancer risk reduction activities

\section{PENDAHULUAN}

Peningkatan jumlah kasus kanker di Indonesia perlu mendapatkan perhatian serius dari berbagai pihak. Data Riset Kesehatan Dasar tahun 2013 melaporkan bahwa prevalensi kanker di Indonesia 1,4 per 1000 penduduk. Angka ini mengalami kenaikan sebesar 350\% dibandingkan data tahun 2007 yang mengungkapkan data prevalesi kanker sebesar 0,4. Melihat situasi ini, penting adanya upaya-upaya pencegahan dan pengendalian penyakit kanker mulai dari pencegahan untuk mengurangi resiko kanker, meningkatkan deteksi dini, penemuan dan tindak lanjut dini kanker, meningkatkan kualitas hidup penderita, serta menurunkan angka kematian akibat kanker. Dari upaya-upaya tersebut, pencegahan kanker termasuk hal penting mengingat bahwa lebih dari $30 \%$ kasus dan kematian akibat kanker diindikasikan disebabkan oleh perilaku dan pola makan. (Dieterich, Stubert, Reimer, Erickson, \& Berling, 2014; Khan,
Adhami, \& Mukhtar, 2010; Song \& Giovannucci, 2016; Steven C. Moore, I-Min Lee, Elisabete Weiderpass, Peter T. Campbell, Joshua N. Sampson, Cari M. Kitahara, Sarah K. Keadle, Hannah Arem, Amy Berrington de Gonzalez, Patricia Hartge, Hans-Olov Adami, Cindy K. Blair, Kristin B. Borch, 2016) Perubahan perilaku dan pola makan juga diperkirakan bisa mengurangi resiko kanker sebesar 29\% .(Adami, H.O., Day, N.E., Trichopoulos, D., Willet, 2001) Pendeteksian dini yang memungkinkan ditemukannya kanker pada stadium awal, akan memberikan tingkat kesembuhan yang lebih tinggi bagi penderita. (DeSantis, Ma, Sauer, Newman, \& Jermal, 2017; Hiom, 2015). Tetapi, umumnya masyarakat datang berobat ke tempat pelayanan kesehatan dengan kanker dalam kondisi sudah stadium lanjut, sehingga sulit untuk diobati. Hal inilah yang menjadi salah satu penyebab semakin tingginya angka mortalitas kanker payudara dari tahun ke tahun.

Menurut Kementerian Kesehatan Republik Indonesia (Kemenkes RI), kurang meluasnya informasi yang benar 
kepada masyarakat tentang kanker merupakan masalah terbesar dalam penanggulangan kanker. Mensosialisasikan pola hidup sehat diyakini merupakan hal efektif sebagai salah satu upaya untuk mencegah penyakit kanker. Masih menurut Kemenkes RI, sebanyak 43\% dari seluruh kasus kanker dapat dicegah dengan menerapkan pola hidup sehat. Sedangkan 30\% dari kasus kanker dapat disembuhkan bila ditemukan dan diobati pada keadaan ini. (Kementerian Kesehatan Republik Indonesia, 2016)

Kondisi tersebut menunjukkan bahwa pemahaman masyarakat terkait penyakit kanker perlu ditingkatkan. Selain itu kurang meluasnya sosialisasi pada masyarakat tentang pencegahan dan deteksi dini kanker juga merupakan kontributor semakin tingginya kasus kanker di Indonesia. Oleh karena itu upaya-upaya yang mendukung ke arah ini perlu dilakukan. Salah satu upaya untuk meningkatkan pemahaman masyarakat adalah dengan melakukan penyuluhan kesehatan, yang diyakini bisa meningkatkan pemahaman, memunculkan kesadaran juga bisa mendorong perubahan perilaku seseorang. Sosialisasi terhadap masyarakat Indonesia terkait kanker belum banyak dilakukan, sehingga upaya-upaya yang fokus pada upaya pencegahan sangat dibutuhkan.

Desa Rancamanyar merupakan desa yang terletak di Kecamatan Baleendah Kabupaten Bandung, Jawa Barat. Penduduk desa Rancamanyar umumnya bermukim di area sepanjang sungai Citarum. Program Pengabdian Pada Masyarakat belum pernah dilakukan di desa ini khususnya di lingkungan RW 2. Masyarakat di wilayah ini belum pernah mendapatkan penyuluhan tentang kanker dari kalangan akademisi dan kesehatan. Oleh karena itu desa Rancamanyar merupakan pilihan yang tepat untuk meluaskan sosialisasi tentang kanker yang sekaligus meningkatkan pemahaman dan kesadaran masyarakat terkait kanker dan upaya-upaya pencegahannya. Oleh karena itu penelitian ini bertujuan untuk meningkatkan pemahaman dan memunculkan kesadaran masyarakat tentang kanker dan aktivitas-aktivitas yang bisa menurunkan resiko kanker di desa Rancamanyar, Kecamatan Baleendah-Kabupaten Bandung. Harapannya, kegiatan penyuluhan ini bisa menjadi bagian dalam upaya menurunkan angka kejadian kanker dan menurunkan resiko kematian akibat kanker payudara.

\section{METODE}

Penelitian ini dilaksanakan mulai bulan Agustus September 2018, dengan lokasi penyuluhan bertempat di aula Yayasan An Naim, Desa Rancamanyar, Kecamatan Baleendah, Kabupaten Bandung-Jawa Barat. Peralatan penelitian yang digunakan untuk penyuluhan adalah kuesioner untuk melihat tingkat pengetahuan responden tentang kanker, proyektor dan perangkat komputer untuk menayangkan video dan materi yang disampaikan, serta doorprice untuk games di akhir sesi.
Subyek yang terlibat dalam penelitian adalah wanita yang sudah menikah yang tinggal di sekitar lokasi penelitian, dengan jumlah peserta 45 orang. Kriteria inklusi subyek penelitian adalah wanita usia subur umur 25-60 tahun, sudah menikah, berpendidikan minimal SD, dan terdaftar sebagai penduduk tetap di desa Rancamanyar minimal selama 10 tahun. Kriteria inklusinya adalah wanita yang memiliki gangguan mental. Pelaksanaan penelitian ini telah melewati proses review dari Komite Etik Penelitian Universitas Padjadjaran dengan pembebasaan etik nomor 935/UN6.KEP/EC/2018.

Bentuk kegiatan yang dilakukan dalam penelitian ini adalah penyuluhan dengan menggunakan metode berbasis pendidikan masyarakat. Metode ini dilakukan dengan jenis aktivitas yang beragam yaitu ceramah, diskusi, nonton video, dan Tanya jawab berhadiah. Sebelum dilakukan penyuluhan, peserta diminta untuk mengisi kuesioner pre-test untuk melihat pengetahuan awal peserta tentang kanker. Setelah itu di awal penyuluhan, ditayangkan video tentang survivor kanker payudara untuk membangun semangat peserta sehingga mau mengetahui lebih jauh informasi tentang kanker dan cara-cara pencegahannya. Setelah itu dilakukan penyampaian materi pertama tentang kanker dan aktivitas penurun resiko kanker dengan metode presentasi dan diskusi. Kemudian dilanjutkan dengan penyampaian materi kedua dengan metode yang sama. Sesi ini diakhiri dengan sesi tanya jawab berhadiah berupa pertanyaan-pertanyaan seputar materi yang sudah disampaikan. Setelah itu peserta diminta untuk mengerjakan soal kuesioner sebagai post-test. Analisa hasil kuesioner dilakukan dengan menggunakan

\section{HASIL DAN PEMBAHASAN}

Kegiatan penyuluhan berlangsung selama 3 jam yang terdiri dari 1 jam pertama merupakan masa persiapan untuk registrasi dan pembimbingan pengisian inform consent, 2 jam berikutnya merupakan inti penyuluhan berupa penyampaian materi 1, materi 2, dan tanya jawab. Secara keseluruhan seluruh kegiatan penyuluhan berlangsung dengan lancar (Gambar 1), yang ditandai dengan beberapa indikator ketercapaian yaitu:

1. Seluruh peserta hadir tepat waktu

2. Seluruh peserta mengikuti kegiatan sampai acara selesai

3. Pelaksanaan kegiatan berlangsung sesuai dengan agenda yang dicanangkan

4. Penyampaian substansi materi sesuai dengan rancangan pembelajaran

5. Peserta sangat aktif mengikuti sesi diskusi dan tanya jawab berhadiah yang merupakan salah satu indikator ketercapaian penyampaian materi.

Beberapa faktor yang turut mempengaruhi baiknya animo masyarakat dalam mengikuti kegiatan penyuluhan ini adalah pertama, dukungan yang sangat baik dari 
aparat desa setempat, dalam hal ini diwakili oleh Ketua RW 2, Desa Rancamanyar. Ketua RW menghimbau kepada semua peserta untuk mengikuti kegiatan dari awal sampai akhir. Beliau juga mengungkapkan harapannya agar kegiatan pengabdian masyarakat seperti ini bisa berlangsung secara berkelanjutan mengingat sejauh ini program serupa belum pernah menyentuh wilayah ini. Kedua, kerjasama yang baik dari mitra yaitu Pengurus Yayasan Tarbiyatul Insan yang telah membangun komunikasi yang baik dengan pihak aparat desa. Pengurus yayasan menyampaikan penjelasan pendahuluan tentang penelitian yang dilakukan oleh tim peneliti baik kepada aparat desa maupun calon peserta sehingga secara teknis memudahkan pelaksanaan kegiatan penyuluhan. Pengurus yayasan juga memberikan dukungan kepada tim peneliti dengan menyediakan berbagai sarana dan prasarana yang dibutuhkan selama penyuluhan. Ketiga, jenis aktivitas yang bervariasi dengan selalu melibatkan peserta dalam proses penyampaian materi, membuat para peserta nyaman dalam mengikuti proses penyuluhan dari awal sampai akhir. Seluruh kegiatan penyuluhan yang sudah dirancang secara sistematis dalam satu modul pembelajaran lengkap, dirasakan sebagai salah satu faktor yang mendukung kelancaran kegiatan ini.

\section{Peningkatan Pengetahuan Peserta tentang Kanker}

Perubahan tingkat pemahaman peserta tentang kanker hanya ditentukan dari 39 peserta dari 45 total peserta yang hadir. Hal ini karena 3 peserta berusia diatas 60 tahun sehingga tidak sesuai dengan kriteria subyek penelitian, 3 peserta lagi memiliki kesulitan dalam membaca dan memahami bacaan sehingga sehingga validitas hasil kuesionernya diragukan, meskipun semuanya masuk dalam kriteria inklusi pendidikan yaitu minimal lulus Sekolah Dasar (SD). Perubahan tingkat pengetahuan peserta tentang kanker diukur dengan membandingkan hasil post-test dan pre-test. Skor kuesioner pada pre-test berada pada rentang 23\%-73\% dengan pemahaman rata-rata sebelum penyuluhan sebesar $46 \%$. Hasil ini mengalami kenaikan setelah dilakukan pengayaan materi dengan skor post test berada pada rentang 34\%-89\% dengan pemahaman rata-rata setelah penyuluhan sebesar $69 \%$. Dengan demikian metode yang dilakukan pada penelitian ini berhasil meningkatkan pemahaman rata-rata $23 \%$ bagi peserta. (Gambar 2) Peningkatan pemahaman paling kecil terjadi pada peserta dengan kode 1 dan 24 dengan kenaikan pemahaman sebesar 5\%. Sementara itu peningkatan pemahaman tertinggi terjadi pada peserta dengan kode 20 dengan kenaikan pemahaman sebesar $45 \%$. Hasil ini menunjukkan bahwa metode yang digunakan dalam pengayaan materi tentang kanker cukup efektif untuk meningkatan pemahaman peserta tentang kanker dan aktivitas-aktivitas yang bisa menurunkan resiko kanker.

Peningkatan pemahaman peserta terkait kanker selaras dengan ungkapan peserta selama sesi diskusi yang

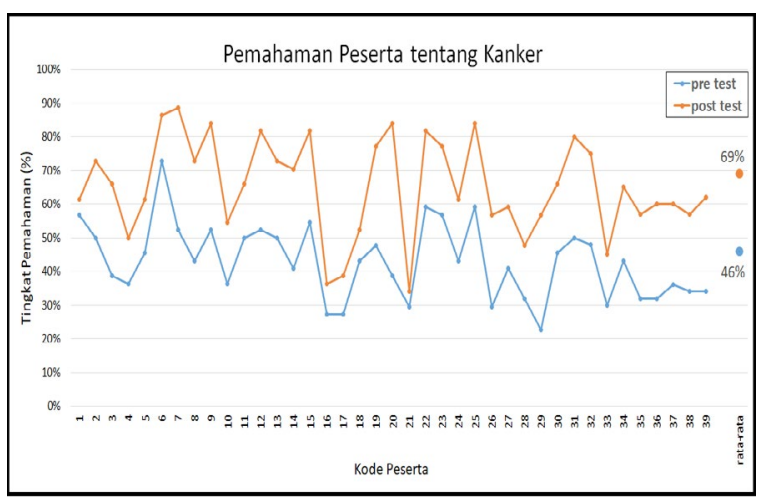

Gambar 2. Peningkatan Pemahaman Peserta tentang Kanker

menunjukkan adanya kesadaran untuk mau bergaya hidup sehat, sebagai upaya untuk menurunkan resiko terkena kanker payudara. Hal ini juga didukung oleh hasil post test yang mengukur aspek afektif peserta, dimana peserta menyatakan akan menyebarkan pengetahuan yang sudah mereka peroleh selama penyuluhan kepada orang lain.

\section{SIMPULAN}

Penyuluhan tentang kanker pada wanita di RW 2 Desa Rancamanyar, Kecamatan Baleendah, Kabupaten Bandung berjalan dengan lancar. Peserta terlihat antusias dalam menerima materi selama kegiatan berlangsung. Pengamatan ini senada dengan hasil kuesioner dimana program penyuluhan kanker ini berhasil meningkatkan pemahaman rata-rata peserta sebesar $23 \%$, dengan pemahaman berada pada rentang 34\%-89\%. Penyuluhan ini juga berhasil memunculkan aspek afektif peserta untuk menyebarluaskan pengetahuan tentang kanker yang sudah diperoleh kepada orang lain. Hasil penelitian ini diharapkan bisa menjadi bagian dari upaya pencegahan kanker payudara sehingga jumlah kasus dan kematian akibat kanker payudara bisa menurun.

\section{UCAPAN TERIMAKASIH}

Ucapan terimakasih penulis sampaikan kepada Direktorat Riset, Pengabdian Kepada Masyarakat, dan Inovasi (DRPMI) Universitas Padjadjaran yang telah mendanai penelitian ini sehingga bisa berjalan dengan baik. Ucapan terima kasih juga penulis sampaikan kepada Yayasan Tarbiyatul Insan An Naim, Aparatur Desa Rancamanyar, dan Komunitas Percantik yang telah menjadi mitra dalam pelaksanaan penelitian ini.

\section{DAFTAR PUSTAKA}

Adami, H.O., Day, N.E., Trichopoulos, D., Willet, W. C. (2001). Primary and secondary prevention in the reduction of cancer morbidity and mortality. Eur $J$ Cancer, 37, 118-127.

DeSantis, C. E., Ma, J., Sauer, A. G., Newman, L. A., \& Jermal, A. (2017). Breast Cancer Statistics , 2017, Racial Disparity in Mortality by State. A Cancer Journal for Clinicians, 67(6), 439-448. 
Dieterich, M., Stubert, J., Reimer, T., Erickson, N., \& Berling, A. (2014). Influence of lifestyle factors on breast cancer risk. Breast Care, 9(6), 407-414.

Hiom, S. C. (2015). Diagnosing cancer earlier: reviewing the evidence for improving cancer survival. British Journal of Cancer, 112(s1), S1-S5. https://doi. org/10.1038/bjc.2015.23

Kementerian Kesehatan Republik Indonesia. (2016). Profil Kesehatan Indonesia 2016. Profil Kesehatan Provinsi Bali.

Khan, N.,Adhami, V. M., \& Mukhtar, H. (2010). Apoptosis by dietary agents for prevention and treatment of prostate cancer. Endocrine-Related Cancer, 17(1), $1-20$.

Song, M., \& Giovannucci, E. (2016). Preventable incidence and mortality of carcinoma associated with lifestyle factors among white adults in the United States. JAMA Oncology, 2(9), 1154-1161.

Steven C. Moore, I-Min Lee, Elisabete Weiderpass, Peter T. Campbell, Joshua N. Sampson, Cari M. Kitahara, Sarah K. Keadle, Hannah Arem, Amy Berrington de Gonzalez, Patricia Hartge, HansOlov Adami, Cindy K. Blair, Kristin B. Borch, and A. V. P. (2016). Leisure-time physical activity and risk of 26 types of cancer in 1.44 million adults. JAMA Intern Med, 176(6), 816-825. 